\title{
Effect of Hydrophobic Interaction on Structure, Dynamics, and Reactivity of Water
}

\author{
Surajit Rakshit, Ranajay Saha, Amrita Chakraborty, and Samir Kumar Pal* \\ Department of Chemical, Biological \& Macromolecular Sciences, S.N. Bose National Centre for Basic Sciences, Block JD, Sector III, \\ Salt Lake, Kolkata 700098, India
}

ABSTRACT: The effect of hydrophobic interaction on water is still controversial and requires more detailed experimental and theoretical investigation. The interaction between organic-water molecular complexes might be indicative of the perturbation of hydrogen-bond network in the tetrahedral structure of bulk waters, due to hydrophobic effect. In this contribution, femto/picosecond-resolved solvation dynamics techniques have been adopted to explore the dynamical modification of water clusters in hydrophobic solvent methyl tert-butyl ether (MTBE). The dynamical evolution of water

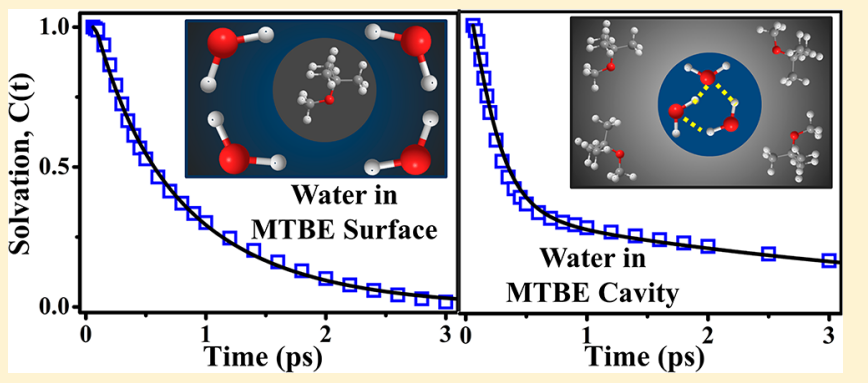
molecules at the surface of micelle-like MTBE has also been studied. Dynamic light scattering techniques have been employed to determine the size of the molecular clusters being formed in respective solvents. Fourier transform infrared (FTIR) spectroscopy well measures the changes in O-H vibration frequency of water induced by MTBE. We have also monitored temperature dependent picosecond-resolved solvation dynamics in order to explore the energetics associated with water solvation in bulk MTBE. Using detailed ab initio calculations at the MP2 level, our study attempts to predict the possible structures, energies, and thermochemical parameters of corresponding MTBE-water molecular complexes in more detail. The chemical reactivity of water further confirms the effect of the hydrophobic interaction on water molecules. The results impart an understanding on hydrophobic interaction imposed by a biomolecule on the structure and reactivity of water, significant for the in vivo cellular condition.

\section{INTRODUCTION}

Segregation of nonpolar molecules from water is commonly known as the hydrophobic effect ${ }^{1}$ and is the key to many biological processes, including protein folding, formation of various self-assemblies (like lipid bilayers), molecular recognition, etc. ${ }^{2-4}$ However, the hydrophobic interaction imposed by a biomolecule on water is quite complex, and so forth to the presence of variety of polar and nonpolar side chains. ${ }^{5}$ The range of possible interactions is too vast even for experimental studies, that simple organic model systems are usually chosen as an alternative. To this end, great efforts have been directed toward understanding the interactions of water with organic molecules. Especially the organic molecule that contains a hydrophobic backbone along with the hydrophilic group is a good prototype for studying the chemical heterogeneity, without the additional effect of topological disorder, typical of protein surfaces. Notably, in all these systems, the hydrophobic interaction seems to cause clustering of water molecules ${ }^{6}$ or hydrophobic units ${ }^{7,8}$ in respective solvents. Therefore, such systems provide a rare opportunity for studying the effect of hydrophobic interaction on water molecules, which also mimics the isolated buried water present in biological systems such as the protein interior. ${ }^{9-11}$ Hence, there are numerous experimental and theoretical studies regarding the organic-water molecular complexes. Infrared spectroscopic studies have been conducted to elucidate the perturbation of hydrogen bonding network of water molecules in presence of nonpolar organic solvents. ${ }^{12-16}$ Various studies have been undertaken on the dynamics of such isolated water molecules to see how the translational and rotational dynamics of water molecules changes, by changing the global structural rearrangement of the hydrogen bond network. ${ }^{17-22}$ In spite of all these experimental and theoretical works, the effect of hydrophobic interaction on water structures is not clear enough as the solvents so far used are less hydrophobic, for example, methanol, acetonitrile, dimethyl formamide (DMF), and so forth.

For better understanding, an organic solvent having hydrophobicity similar to the protein interior should be chosen. Methyl tert-butyl ether (MTBE) is an example of such a solvent having a bulky hydrophobic tert-butyl group, along with a less polar $\mathrm{C}-\mathrm{O}$ bond. The choice of MTBE also lies in the fact that the molecule is the most common gasoline oxygenate and has become a widespread contaminant in surface water and groundwater ${ }^{23-29}$ due to its high water solubility $\left(44 \mathrm{~g} \mathrm{~L}^{-1}\right.$ at $20{ }^{\circ} \mathrm{C}$ ). The presence of MTBE in drinking water and groundwater resources causes different physical hazards. Moreover, there is also evidence that MTBE is a possible human carcinogen. ${ }^{30}$ Thus, it is very important to investigate the water-MTBE molecular complexes in considerable detail.

Received: October 27, 2012

Revised: December 11, 2012

Published: January 11, 2013 
Recently, Nielsen et al. ${ }^{31}$ studied the interactions between water and MTBE from a thermodynamic point of view. $\mathrm{Li}$ and Singh $^{32}$ have investigated the interaction of water-MTBE complexes using Fourier transform infrared (FTIR) spectroscopy and ab intio calculations. All these studies suggest that complexation of MTBE with water occurs through hydrogen bonding, and essentially focus on the effect of hydrogen bonding on the MTBE moiety. In spite of all these efforts, our understanding about the changes in the hydrogen bonding network of water moieties under the hydrophobic interaction of MTBE is still limited and requires more detailed investigations. In the present study, we explore the structural and dynamical characterization of water molecules in both water/MTBE and $\mathrm{MTBE} /$ water binary systems. We have used dynamic light scattering (DLS) techniques to determine the size of the clusters being formed in respective solvents. The changes in $\mathrm{O}-\mathrm{H}$ stretching frequency of water, induced by MTBE have been examined using FTIR measurements. Femtosecondresolved fluorescence upconversion technique has been explored to understand the ultrafast internal motions of water molecules. The diffusive translational motion of the water molecules has been revealed using picosecond-resolved time correlated single photon counting (TCSPC) method. Temperature dependent solvation dynamics of water have been studied to understand the energetics of the hydrogen bond network in the clusters. Attempt has also been made to correlate the experimental findings with theoretical estimations. Using detailed $a b$ initio calculations at the MP2 level, we predict the possible lowest energy structures, and corresponding energies and thermodynamic parameters of different MTBEwater molecular complexes. Finally, to correlate the dynamics of water with its reactivity, we have measured solvolysis kinetics of benzoyl chloride $(\mathrm{BzCl})$ in a typical water/MTBE system, at various temperature values.

\section{MATERIALS AND METHODS}

Chemicals. MTBE ( $>99.8 \%$, anhydrous) was purchased from Sigma-Aldrich; benzoyl chloride $(\mathrm{BzCl})$ was purchased from Merck and used without further purification. The fluorescent probe coumarin 500 (C500) was a product of Exciton. Double-distilled water was used for the preparation of water/MTBE and MTBE/water mixtures of different concentrations. For all spectroscopic studies, the concentration of C500 was kept at ca. $5 \mu \mathrm{M}$.

Experimental and Analytical Procedures. Dynamic light scattering (DLS) measurements were done with a Nano $S$ Malvern instrument employing a $4 \mathrm{~mW} \mathrm{He}-\mathrm{Ne}$ laser $(\lambda=632.8 \mathrm{~nm})$ equipped with a thermostatted sample chamber. A JASCO FTIR-6300 spectrometer was used for the FTIR measurements. Each spectrum consists of 100 scans $\left(1500-4000 \mathrm{~cm}^{-1}\right)$ acquired at $0.5 \mathrm{~cm}^{-1}$ resolution. ${ }^{1} \mathrm{H}$ NMR experiments were performed using a Bruker DRX $500 \mathrm{MHz}$ spectrometer, and signals were assigned by comparing with literature.

Steady-state absorption and emission were measured in a Shimadzu UV-2450 spectrophotometer and JobinYvon Fluorolog fluorimeter, respectively, with a temperature controller attachment from Julabo. Femtosecond-resolved fluorescence was measured using a femtosecond upconversion setup (FOG 100, CDP). The details of the upconversion technique have been described in our earlier studies. ${ }^{33}$ For the picosecond-resolved fluorescence measurements, we used a commercially available picosecond diode laser-pumped (LifeSpec-ps) time-resolved fluorescence spectrophotometer from Edinburgh Instruments (Livingston, U.K. (excitation wavelength $375 \mathrm{~nm}, 80$ ps instrument response function (IRF)) and fitted using FAST software provided by Edinburgh Instruments. The details of time-resolved measurements could be found elsewhere. ${ }^{34,35}$ The time dependent fluorescence Stokes shifts, as estimated from TRES (time resolved emission spectroscopy), were used to construct the normalized spectral shift correlation function or the solvent correlation function, $C(t)$ defined as

$$
C(t)=\frac{\nu(t)-\nu(\infty)}{\nu(0)-\nu(\infty)}
$$

where $\nu(0), \nu(t)$, and $\nu(\infty)$ are the emission maxima (in $\mathrm{cm}^{-1}$ ) at time zero, $t$, and infinity, respectively. The $\nu(\infty)$ values had been taken to be the emission frequency beyond which an insignificant or no spectral shift was observed. The $C(t)$ function represents the temporal response of the solvent relaxation process, as occurs around the probe following its photoexcitation and the associated change in the dipole moment. For the kinetic study of $\mathrm{BzCl}$ hydrolysis, a known volume of $\mathrm{BzCl}$ is dissolved in MTBE. The kinetics of $\mathrm{BzCl}$ solvolysis was measured in a Shimadzu UV-2450 spectrophotometer by monitoring the time-dependent change in the absorbance of $\mathrm{BzCl}$ at $288 \mathrm{~nm}$ with varying temperature.

Computational Methods. All theoretical calculations were carried out using the Gaussian 03 program. ${ }^{36}$ The geometries of different MTBE-water complexes were optimized, and the frequency calculations were followed by using both DFT level with B3LYP functional and Møller-Plesset correlation energy correction truncated at second-order (MP2) in conjunction with 6-31g basis set, that is, MP2/6-31g, at the ground state. However, the results obtained from MP2/6-31G are more consistent with the experimental findings, so theoretical calculations at the MP2/6-31G level are only reported. We represented MTBE in water by the model system MTBE/(water) (where, $n=1,2,3$ ) and water in MTBE system by water/(MTBE) ${ }_{n}$ (where, $n=1,2,3$ ). Each of these species is the minimum energy structure as all the normal modes of vibrations are positive. Binding energy $(\Delta E)$ of MTBE-water complexes was determined from calculation at the MP2 level. Calculated energy values included both zero point correction $(\triangle \mathrm{ZPE})$ and basis set superposition error (BSSE) in the counterpoise method, for more accurate results. Energy of the prototype hydrogen bond was also calculated from the water dimer at the same level. Thermochemical parameters such as enthalpy of formation and Gibbs free energy change in forming molecular clusters from monomers were estimated using the following equations: ${ }^{37}$

$$
\Delta H=H_{\text {product }}-H_{\text {reactant }}=H_{\mathrm{MTBE}-\left(\mathrm{H}_{2} \mathrm{O}\right)_{n}}-\left(H_{\mathrm{MTBE}}+n \mathrm{H}_{\mathrm{H}_{2} \mathrm{O}}\right)
$$

and

$$
\Delta G=G_{\text {Product }}-G_{\text {Reactant }}=G_{\mathrm{MTBE}-\left(\mathrm{H}_{2} \mathrm{O}\right)_{n}}-\left(G_{\mathrm{MTBE}}+n G_{\mathrm{H}_{2} \mathrm{O}}\right)
$$

\section{RESULTS AND DISCUSSION}

MTBE in Water (MTBE/Water). It is known that organic molecules tend to form clusters when solubilized in water. ${ }^{38}$ To reveal the microscopic behavior of MTBE/water binary system, DLS experiments have been carried out. Figure la shows the DLS signals of the MTBE/water system $(60 \mu \mathrm{L} / \mathrm{mL}, \mathrm{v} / \mathrm{v})$, at room temperature with the cluster size being $800 \mathrm{~nm}$. It can be emphasized here that the distribution profile is unimodal in both intensity $\left(\propto d^{6}\right)$ distribution as well as in volume $\left(\propto d^{3}\right)$ distribution profile ( $d$ being the diameter of the clusters) with relatively low $(\sim 0.3)$ polydispersity index (PDI), suggesting the existence of aggregates of uniform sizes. The high value of hydrodynamic diameter $\left(d_{\mathrm{H}}\right)$ could be argued due to the formation of micelle-like aggregate structures in water, ${ }^{8}$ and offers a unique opportunity to investigate the effect of hydrophobic interactions on the dynamic behavior of water, quite significant with respect to the in vivo cellular environment. The formation of the micelle-like clusters of MTBE in water is also supported by thermochemical studies of the binary 

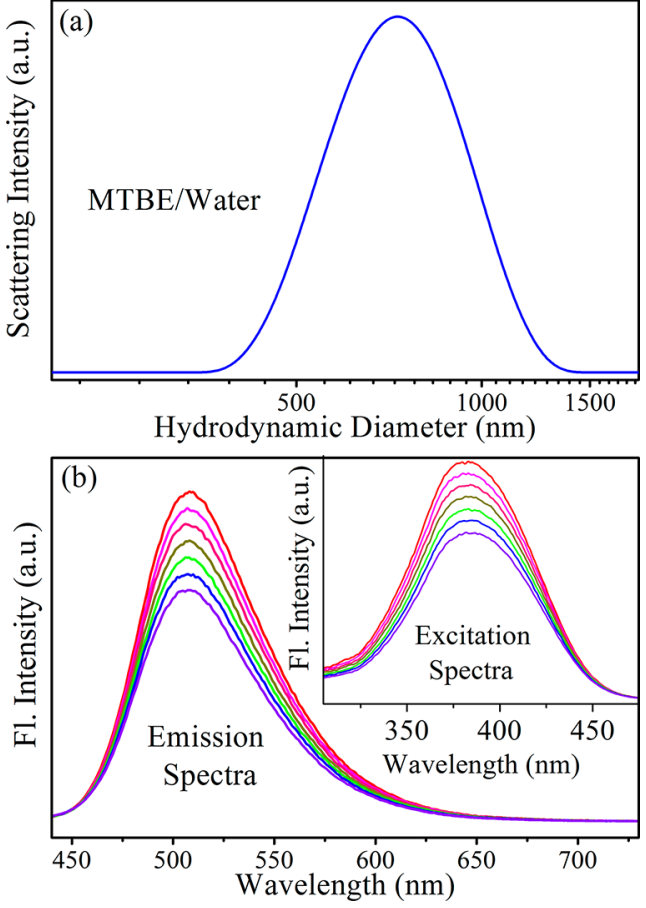

Figure 1. (a) DLS spectrum of MTBE/water mixture at MTBE concentration of $60 \mu \mathrm{L} / \mathrm{mL}(\mathrm{v} / \mathrm{v})$. (b) Normalized emission spectra $\left(\lambda_{\mathrm{ex}}=375 \mathrm{~nm}\right)$ of C500 in MTBE/water system with different MTBE concentrations $(0,10,20,30,40,50,60 \mu \mathrm{L} / \mathrm{mL})$. Corresponding normalized excitation spectra $\left(\lambda_{\mathrm{em}}=510 \mathrm{~nm}\right)$ is shown in the inset. (Both the excitation and emission spectra of C500 in different MTBE concentrations are conveniently normalized to show the insignificant change in the respective peak positions.)

eutectic melt of the system using DSC measurement. ${ }^{39}$ The negative enthalpy of mixing $\left(\Delta_{\text {mix }} H=-1.2 \mathrm{~kJ} \mathrm{~mol}^{-1}\right)$ for the MTBE/water system suggests the clustering of MTBE molecules in the eutectic melt of the binary system. ${ }^{39}$

To probe the dynamics of the water molecules in the microenvironment of the clusters, coumarin 500 (C500) is used as a solvation probe. C500 is sparingly soluble in water and shows a large solvatochromic effect (solvation) in polar and nonpolar medium. ${ }^{22,40}$ Figure $1 \mathrm{~b}$ depicts the steady-state excitation (inset) and emission spectra of C500 in different concentrations of MTBE. It is important to note that, in pure MTBE, the emission peak of C500 is at ca. $450 \mathrm{~nm}$ (Figure 5), and it is red-shifted to $515 \mathrm{~nm}$ in bulk water (figure not shown). The observed red shift in the peak position of C500 to ca. $508 \mathrm{~nm}$ in the MTBE/water system compared to that in bulk MTBE suggests that C500 resides at the highly restricted polar environment of MTBE-water interface projecting more toward bulk water. Consequently, the observed insignificant change in the excitation and emission peak positions of C500 (Figure 1b) with varying MTBE concentrations suggests the essential location of the probe at the water-MTBE interface in all the studied concentrations of MTBE.

The probe C500 has previously been used to report the solvation dynamics of water in various restricted environments. ${ }^{7,22,33,40}$ In the present contribution, we investigate the dynamics of water molecules in the micelle-like clusters of $\mathrm{MTBE} /$ water binary mixture using $\mathrm{C500}$ as a solvation probe. Figure 2a depicts the femtosecond-resolved fluorescence decay transients of C500 in a MTBE/water mixture $(60 \mu \mathrm{L} / \mathrm{mL}, \mathrm{v} / \mathrm{v})$. At the blue end of the spectrum $(460 \mathrm{~nm})$, the signal decays
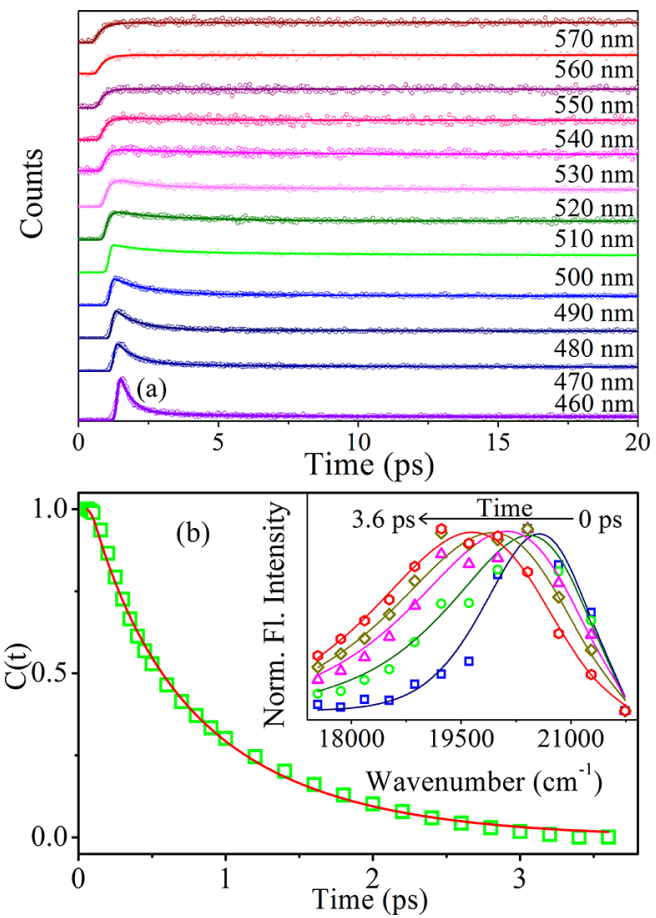

Figure 2. (a) Femtosecond-resolved fluorescence transients $\left(\lambda_{\mathrm{ex}}=385\right.$ $\mathrm{nm})$ of C500 at different detection wavelengths in MTBE/water mixture with $\mathrm{MTBE}$ concentration $60 \mu \mathrm{L} / \mathrm{mL}$. (b) Solvation correlation function, $\mathrm{C}(\mathrm{t})$, of $\mathrm{C} 500$ in $\mathrm{MTBE} /$ water mixture with MTBE concentration of $60 \mu \mathrm{L} / \mathrm{mL}$. Corresponding TRES in MTBE/ water mixture are shown in the inset.

with time constants of 410 fs (84\%), 3 ps (9\%), and 3700 ps $(7 \%)$, and at the red end $(570 \mathrm{~nm})$ the transient rises in $280 \mathrm{fs}$ (49\%) with subsequent decay in $3700 \mathrm{ps}(51 \%)$. The initial femtosecond decay at the blue side and the rise at the red side dominantly result from solvation stabilization processes, ${ }^{33-35,41}$ which is associated with the spectral shift of $926 \mathrm{~cm}^{-1}$ in the 3.6 ps window (Figure 2b, inset). Following TRES, we construct the solvent correlation function, $C(t)$, to obtain the solvation time, $\left\langle\tau_{\mathrm{s}}\right\rangle\left(=\sum a_{\mathrm{i}} \tau_{\mathrm{i}}\right)$, as shown in Figure $2 \mathrm{~b}$. The temporal decay of $C(t)$ (Table 1) shows biexponential decay with time

Table 1. Femtosecond-Resolved Solvent Correlation Function Time Scales for C500 in MTBE/Water ([MTBE] = $60 \mu \mathrm{l} / \mathrm{mL}$ ) and Water/MTBE ([water $]=5 \mu \mathrm{L} / \mathrm{mL}$ ) Mixtures

\begin{tabular}{cccccc} 
system & $a_{1}$ & $\tau_{1}(\mathrm{ps})$ & $a_{2}$ & $\tau_{2}(\mathrm{ps})$ & $\left\langle\tau_{\mathrm{s}}\right\rangle(\mathrm{ps})$ \\
MTBE/water & 0.28 & 0.32 & 0.72 & 0.92 & 0.75 \\
water/MTBE & 0.74 & 0.20 & 0.26 & 4.03 & 1.20 \\
\hline
\end{tabular}

constants $\left(\tau_{\mathrm{i}}\right)$ of 322 and 920 fs. Femtosecond-resolved studies by Maroncelli et al. ${ }^{42}$ and Barbara et al. ${ }^{43}$ reveal that the solvation response of bulk water is bimodal revealing a fast inertial response indicating librational motion and a slower diffusional motion. In a recent study from our group, we have explored the nature of solvation dynamics of bulk water (C500 as fluorescent probe) with time constants 330 and $710 \mathrm{fs}^{33}$ Thus, femtosecond-resolved fluorescence upconversion study of C500 in the MTBE/water system suggests the dynamic behavior of water to be quite similar to that of the bulk water.

To quantify the energetics associated to the interaction process, we calculate the free energy change $\left(\Delta G^{\ddagger}\right)$ using the Eyring equation, ${ }^{44}$ 


$$
k=\frac{1}{\left\langle\tau_{\mathrm{s}}\right\rangle}=\left(\frac{k_{\mathrm{B}} T}{h}\right) \exp \left(\frac{-\Delta G^{\ddagger}}{R T}\right)
$$

where $k_{\mathrm{B}}$ the Boltzmann constant, $h$ Plank's constant, and $k$ the rate constant at temperature $T$. From our previous results of femtosecond dynamics of bulk water, ${ }^{33}$ we calculate the Gibbs free energy of solvation to be $\sim 750 \mathrm{cal} \mathrm{mol}^{-1}$. However, inclusion of MTBE molecules into water increases the free energy change of the system to $\sim 900 \mathrm{cal} \mathrm{mol}^{-1}$, and is due to the possible perturbation of hydrogen-bonding network of water molecules by the MTBE induced interactions.

To further investigate the genesis of the interaction, $a b$ initio calculations have been performed for MTBE-water complexes. We consider simple model systems, where with one MTBE molecule, $n$ (number of water molecules), can interact such that $\mathrm{MTBE}+n \mathrm{H}_{2} \mathrm{O} \rightarrow \mathrm{MTBE} /(\text { water })_{n}$, where $n=1,2,3$, and so forth. Based on our computation results, it is found that addition of third water molecule does not affect the number of hydrogen bonds in the MTBE- $\left(\mathrm{H}_{2} \mathrm{O}\right)_{2}$ complex; that is, a third water molecule does not impose any effective contribution to the hydrogen bonding network between MTBE and water. Accordingly, we focus on the hydrogen bonding interaction within MTBE/(water) ${ }_{n}$ complexes with $n=1,2$.

We first choose water dimer, the benchmark system for hydrogen bonding study, and calculate the energy parameters associated with hydrogen bonding at the MP2/6-31g level. We find the binding energy $(\Delta E)$ and enthalpy $(\Delta H)$ of dimerization to be $\sim 4$ and $\sim-6 \mathrm{kcal} \mathrm{mol}^{-1}$, respectively, which are similar to the previously estimated experimental/ theoretical values. ${ }^{45-47}$ The close agreement of the experimental and calculated results for the water dimer leads us to estimate the energy parameters for MTBE-water complexes at the same level. Distinct energy parameters for different MTBE-water complexes are shown in Table 2. When one

Table 2. Calculated Energy Parameters of MTBE-Water Complexes at MP2/6-31g Level

\begin{tabular}{cccc} 
systems & $\begin{array}{c}\Delta E_{\text {bsse+zpc }} \\
\left(\mathrm{kcal} \mathrm{mol}^{-1}\right)\end{array}$ & $\begin{array}{c}\Delta G(\mathrm{cal} \\
\left.\mathrm{mole}^{-1}\right)\end{array}$ & $\begin{array}{c}\Delta H \\
\left(\mathrm{kcal} \mathrm{mol}^{-1}\right)\end{array}$ \\
$\mathrm{MTBE} /(\text { water })_{1}$ & 3 & 439 & -8 \\
$\mathrm{MTBE} /(\text { water })_{2}$ & 6.5 & 753 & -17 \\
water/(MTBE $)_{2}$ & 5 & 2700 & -12.55 \\
\hline
\end{tabular}

water molecule is added to MTBE, one of the hydrogen atoms within the water molecule interacts with oxygen atom of MTBE, by forming a hydrogen bond $\left(\mathrm{O}_{2} \cdots \mathrm{H}_{20}\right)$ with a bond length of $1.84 \AA$ (Figure 3). Computed $\Delta E$ for $\mathrm{MTBE} /(\text { water })_{1}$ complex is $\sim 3 \mathrm{kcal} \mathrm{mol}^{-1}$, which is quite close to hydrogen bond energy of water. When two water molecules are added to MTBE molecule, MTBE/ $\left(\mathrm{H}_{2} \mathrm{O}\right)_{2}$ is formed. As shown in Figure 3, there is a possibility of formation of three hydrogen bonds in this complex. Both the water molecules form a hydrogen bond with the oxygen atom of MTBE, with bond lengths of $\left(\mathrm{O}_{2} \cdots \mathrm{H}_{2} \mathrm{O}\right) \quad 1.64 \AA$ and $\left(\mathrm{O}_{2} \cdots \mathrm{H}_{24}\right) \quad 2.17 \AA$, respectively, and internal hydrogen bond between two water molecules $\left(\mathrm{O}_{19} \cdots \mathrm{H}_{23}\right)$ with bond length of $1.67 \AA$. Calculated $\Delta E$ is $\sim 6.5 \mathrm{kcal} \mathrm{mol}^{-1}$. Calculation of thermochemical parameters shows that complexation between MTBE-water is an exothermic process with the estimated change in enthalpy $(\Delta H)$ of $-8 \mathrm{kcal} \mathrm{mol}^{-1}$ (for $\mathrm{MTBE}-\left(\mathrm{H}_{2} \mathrm{O}\right)_{1}$, a single $\mathrm{H}$ bonded system) and $-17 \mathrm{kcal} \mathrm{mol}^{-1}$ (for $\operatorname{MTBE}-\left(\mathrm{H}_{2} \mathrm{O}\right)_{2}$, three H-bonded system). Thus, enthalpy analysis essentially

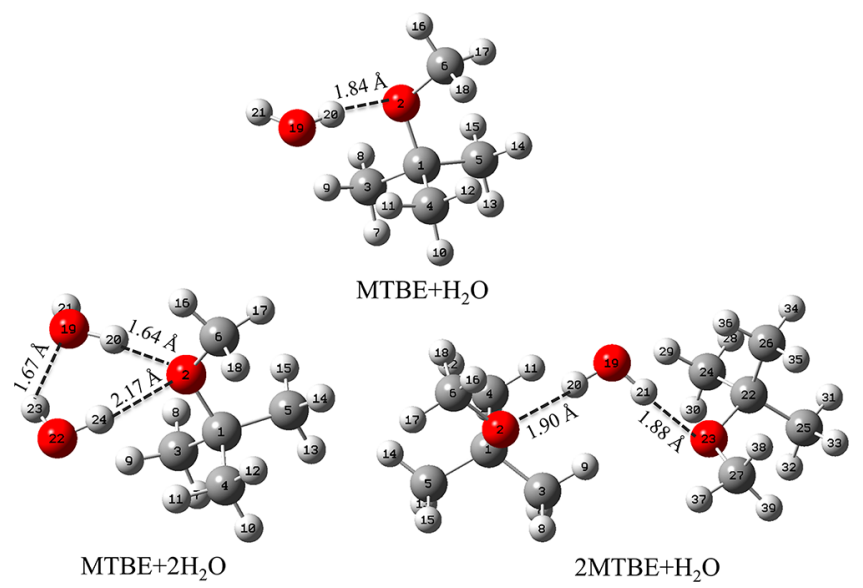

Figure 3. Optimized structures of different MTBE-water complexes at the MP2/6-31g level. The red ball indicates the oxygen atom, dark gray ball indicates the carbon atom, and white ball indicates the hydrogen atom. Dotted lines indicate hydrogen bonding between two atoms.

predicts the energy release due to formation of MTBE- $\left(\mathrm{H}_{2} \mathrm{O}\right)_{1}$ complex is quite close to the enthalpy of formation for intermolecular water-water hydrogen bond in the water dimer. The enthalpy is also found to increase with the increase in the number of hydrogen bonds, revealing the complexation process to be thermodynamically more favorable. The calculated free energy change $(\Delta G)$ associated with the complexation process of $\mathrm{MTBE} /$ (water) $)_{n=1,2}$ is found to be ca. 439 and $753 \mathrm{cal} \mathrm{mol}^{-1}$, respectively, which is in the same order of magnitude as our experimental findings of the free energy change associated with the solvation process. Accordingly, theoretical studies clearly indicate that hydrogen bonding interaction between MTBE and water plays the crucial role, and as such the calculated $\Delta G$ of complexation is largely contributed by the solvation process.

Water in MTBE (Water/MTBE). Figure 4a depicts the DLS spectrum of the water/MTBE system $(5 \mu \mathrm{L} / \mathrm{mL}, \mathrm{v} / \mathrm{v})$, showing the appearance of a DLS of peak at around $7 \mathrm{~nm}$. The DLS peak is monodispersed and suggests the formation of water clusters in the MTBE continuum. It was found that water forms very small clusters of 2-10 water molecules in the hydrophobic environment of organic solvents, and the molecular origin of this interaction is water-organic hydrogen bonding. 6,8 To study the water-MTBE hydrogen bonding interaction, we perform FTIR measurements of the water clusters, as shown in Figure $4 \mathrm{~b}$. In the frequency region of $3000-4000 \mathrm{~cm}^{-1}$, the spectrum has three absorption peaks at around 3693, 3573, and $3507 \mathrm{~cm}^{-1}$. The band at $3693 \mathrm{~cm}^{-1}$ is due to the $\mathrm{O}-\mathrm{H}$ stretching mode of isolated water molecules. The intense peaks at 3573 and $3507 \mathrm{~cm}^{-1}$ are due to the $\mathrm{O}-\mathrm{H}$ stretching mode of hydrogen bonded water molecules, forming "one-bonded" complex of $\mathrm{H}-\mathrm{O}-\mathrm{H}:: \mathrm{OMe}\left({ }^{t} \mathrm{Bu}\right)$ (where $\left({ }^{t} \mathrm{Bu}\right) \mathrm{MeO}$ stands for $\mathrm{MTBE})$ and "two-bonded" complex of $\left({ }^{t} \mathrm{Bu}\right) \mathrm{MeO}: \mathrm{H}-\mathrm{O}-$ $\mathrm{H}:: \mathrm{OMe}\left({ }^{t} \mathrm{Bu}\right)$, respectively. Similar results have been found for $\mathrm{O}-\mathrm{H}$ stretching of water dissolved into the solution of other ethers, including di- $n$-butyl ether (BE) and di- $n$-octyl ether (OE). ${ }^{13}$ Notably, in the FTIR spectrum, the $\mathrm{O}-\mathrm{H}$ bending of water at $1645 \mathrm{~cm}^{-1}$ is found to be red-shifted by about $12 \mathrm{~cm}^{-1}$ in MTBE and is possibly due to hydrogen bond formation with MTBE. $^{48}$ Formation of hydrogen bond with MTBE is also reflected in ${ }^{1} \mathrm{H}$ NMR spectra. The upper and middle panels of Figure $4 c$ show the proton NMR signal of water and MTBE, 

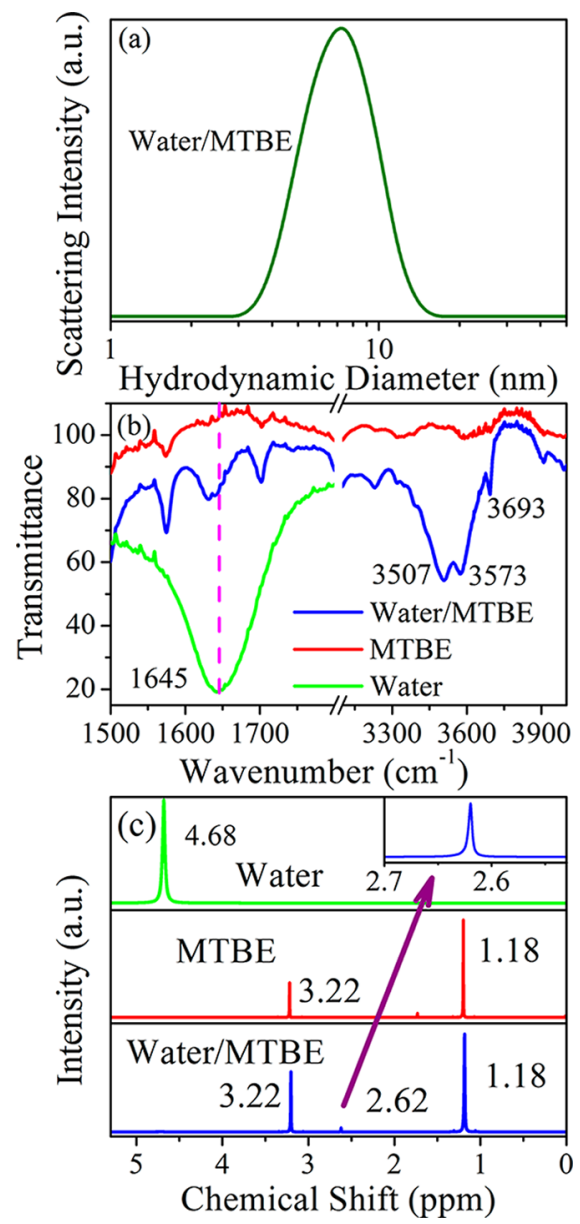

Figure 4. (a) DLS signals of water/MTBE system ([water $]=5 \mu \mathrm{L} /$ $\mathrm{mL}$ ) at $293 \mathrm{~K}$. (b) FTIR spectra of pure water, pure MTBE, and water/MTBE mixture with water concentration of $5 \mu \mathrm{L} / \mathrm{mL}$. (c) ${ }^{1} \mathrm{H}$ NMR spectra of water, MTBE, and water/MTBE mixture with water concentration of $5 \mu \mathrm{L} / \mathrm{mL}$. Inset shows the zoomed view of the newly generated peak at $2.62 \mathrm{ppm}$ due to hydrogen bond formation of water with MTBE.

respectively. The ${ }^{1} \mathrm{H}$ NMR signal for water found is at 4.68 ppm, whereas for MTBE it is found at 3.22 (for $-\mathrm{OCH}_{3}$ ) and 1.18 (for $-\mathrm{CCH}_{3}$ ) ppm, ${ }^{49}$ respectively. However, for the water/MTBE system, the ${ }^{1} \mathrm{H}$ NMR spectra (lower panel of Figure 4c) shows an extra peak (instead of 4.68, 3.22, and 1.18 $\mathrm{ppm})$ at around $2.62 \mathrm{ppm}$ because of the increased electron density around the water proton as intermolecular hydrogen bond formed with the oxygen of MTBE and hence the chemical shift decreases. ${ }^{50}$

The observed changes in the $\mathrm{O}-\mathrm{H}$ vibration band of water in presence of MTBE can also lead to dynamical properties different from the bulk properties as observed previously for water in dioxane. ${ }^{21,22}$ We have studied the dynamical properties of water clusters using C500 as fluorophore. Figure 5a and b shows the absorption and emission spectra of C500 in various water/MTBE mixtures, respectively. Both absorption and fluorescence bands shift further to the red side with increasing concentration of water. It can be argued that with increasing water content the probe experiences more polar environment, which produces the observed red shift. ${ }^{40}$ The above observation can further be validated from the difference of the absorption spectrum of C500 in water/MTBE mixture from that in MTBE. The difference absorption spectrum exhibits a negative
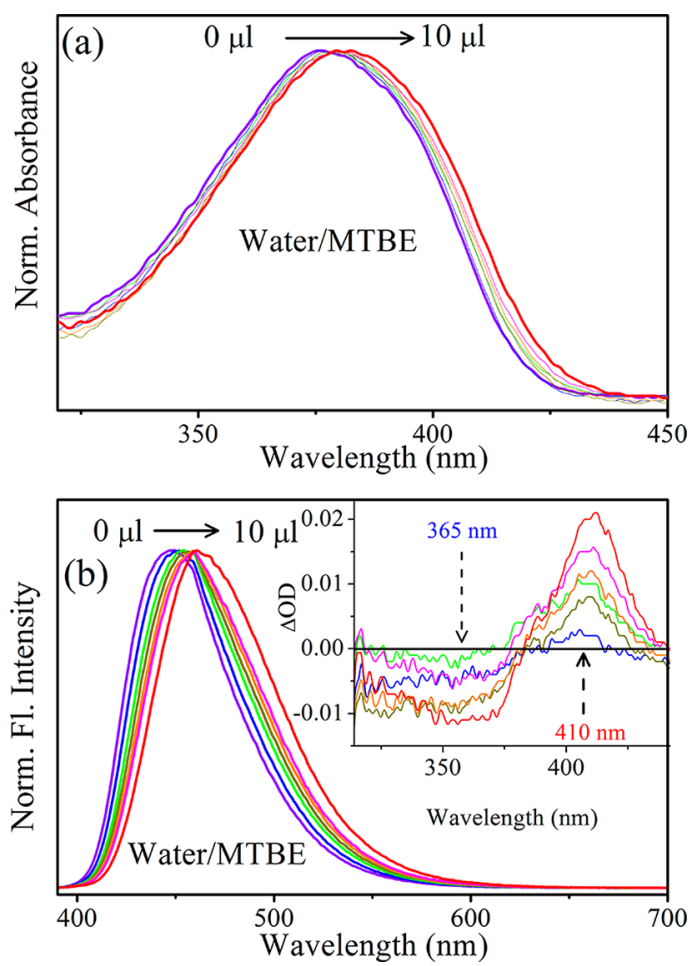

Figure 5. Absorption (a) and emission (b) spectra of C500 ( $\lambda_{\mathrm{ex}}=375$ $\mathrm{nm}$ ) in the water/MTBE system with different water concentrations. Difference absorption spectra of C500 in the water/MTBE system with respect to C500 in MTBE in different water concentrations are presented in the inset of (b).

absorption at $365 \mathrm{~nm}$ and a distinct positive peak at $410 \mathrm{~nm}$ (Figure 5b, inset). The negative absorption peak clearly indicates that, upon addition of water, the population of C500 in the bulk MTBE decreases. On the other hand, the emergence of the positive absorption peak at $410 \mathrm{~nm}$ is due to the C500 molecules migrating to a higher polar region of the water-MTBE interface. In order to investigate the dynamics of water molecules, we have performed femtosecond-resolved fluorescence spectroscopic technique for the binary mixture containing $5 \mu \mathrm{L} / \mathrm{mL}$ of MTBE in water. Figure 6a shows the femtosecond decay transients of C500 for a series of detected fluorescence wavelengths. It is clear from the figure that the fluorescence transients are strongly wavelength dependent showing a faster decay in the blue end and eventual rise in the red end of the emission spectrum, which is indicative of solvation of the probe in the binary mixture. ${ }^{33-35}$ Using the decay transients at different wavelengths, we construct the TRES (Figure 6b; inset), wherein a significant dynamic fluorescence Stokes shift of $700 \mathrm{~cm}^{-1}$ in 15 ps is observed. Figure $6 \mathrm{~b}$ depicts the solvent correlation function, $C(t)$, of the system. As shown in the figure, $C(t)$ can be fitted biexponentially with time components of 0.20 ps (74\%) and 4.03 ps $(26 \%)$ (Table 1), which are quite similar to those obtained for a water-dioxane mixture. ${ }^{22}$ The origin of the observed slower component is due to the cooperative relaxation of the hydrogen bond network of water, whereas the faster subpicosecond time scale arises due to the relaxation of water molecules that are not part of the tetrahedral hydrogen bond network of the water clusters, that is, the isolated water molecules, or the water molecules forming weak hydrogen bonds with the ether oxygen of MTBE, that is, "one-bonded" or "two-bonded" complex of water molecules mentioned earlier. 

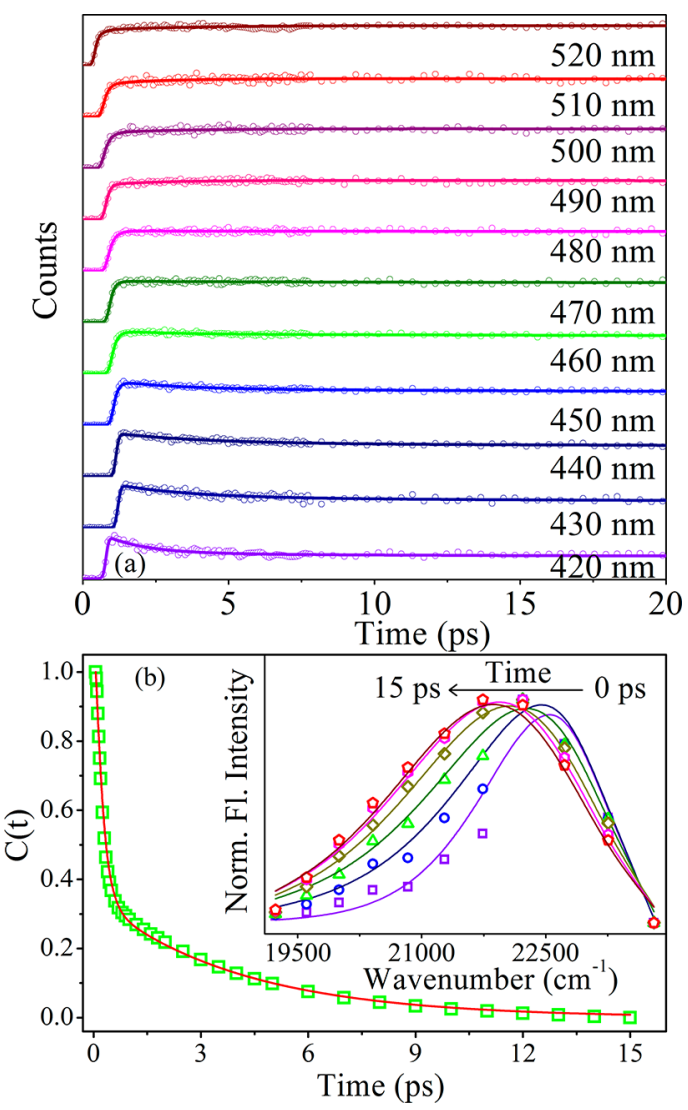

Figure 6. (a) Femtosecond-resolved decay transients $\left(\lambda_{\text {ex }}=385 \mathrm{~nm}\right)$ of C500 at different wavelengths in water/MTBE system ([water] $=5$ $\mu \mathrm{L} / \mathrm{mL}$ ) at $293 \mathrm{~K}$. (b) Solvent correlation function, $C(t)$, of C500 in water/MTBE system ([water $]=5 \mu \mathrm{L} / \mathrm{mL}$ ). The corresponding TRES is shown in the inset.

Using the Eyring equation, we calculate the $\Delta G^{\ddagger}$ of the system to be $1200 \mathrm{cal} \mathrm{mol}^{-1}$, which is quite consistent with the theoretically calculated value as discussed below.

The thermochemical calculations on the model system $\mathrm{H}_{2} \mathrm{O}$ / (MTBE) ${ }_{n}$ (where $n=1,2,3$ ) are similarly performed, assuming that, in the water/MTBE system, a water molecule is surrounded by $n$ number of MTBE molecules. In our calculation, the $n$ value is limited up to 2 , because higher $n$ (>2) does not affect the $\mathrm{H}$-bonding network in the $\mathrm{H}_{2} \mathrm{O}$ / $(\mathrm{MTBE})_{2}$ complex. The corresponding energy optimized molecular structure of the $\mathrm{H}_{2} \mathrm{O} /(\mathrm{MTBE})_{2}$ complex can be seen in Figure 3, showing two MTBE molecules forming hydrogen bonds with one water molecule with bond lengths $\left(\mathrm{O}_{23} \cdots \mathrm{H}_{21}\right) 1.88 \AA$ and $\left(\mathrm{O}_{2} \cdots \mathrm{H}_{20}\right) 1.90 \AA$, respectively. The $\Delta E$ for water/(MTBE) system is found to be $3 \mathrm{kcal} \mathrm{mol}^{-1}$, whereas for the water $/(\mathrm{MTBE})_{2}$ system the value is $5 \mathrm{kcal} \mathrm{mol}^{-1}$. The corresponding $\Delta H$ for complexation in water/(MTBE) and water/(MTBE $)_{2}$ is found to be exothermic in nature with calculated values of ca. -8 and $-12.55 \mathrm{kcal} \mathrm{mol}^{-1}$, respectively (Table 2). The calculated $\Delta G$ value for the water $/(\mathrm{MTBE})_{2}$ system is found to be ca. $2700 \mathrm{cal} \mathrm{mol}^{-1}$, which is quite consistent with the experimentally estimated value for $\Delta G$ of solvation.

Water clusters in nonpolar solvent have been reported to exhibit slow solvation dynamics at the picosecond time scale. ${ }^{7,22,51}$ This slow solvation has been concluded to be due to the translational diffusion of water in the solvation shell displacing the nonpolar solvent molecules in the cluster. To get insight on the slow dynamics of the water/MTBE system, we perform picosecond-resolved fluorescence spectroscopy using TCSPC setup. Figure $7 \mathrm{a}$ depicts the fluorescence decay
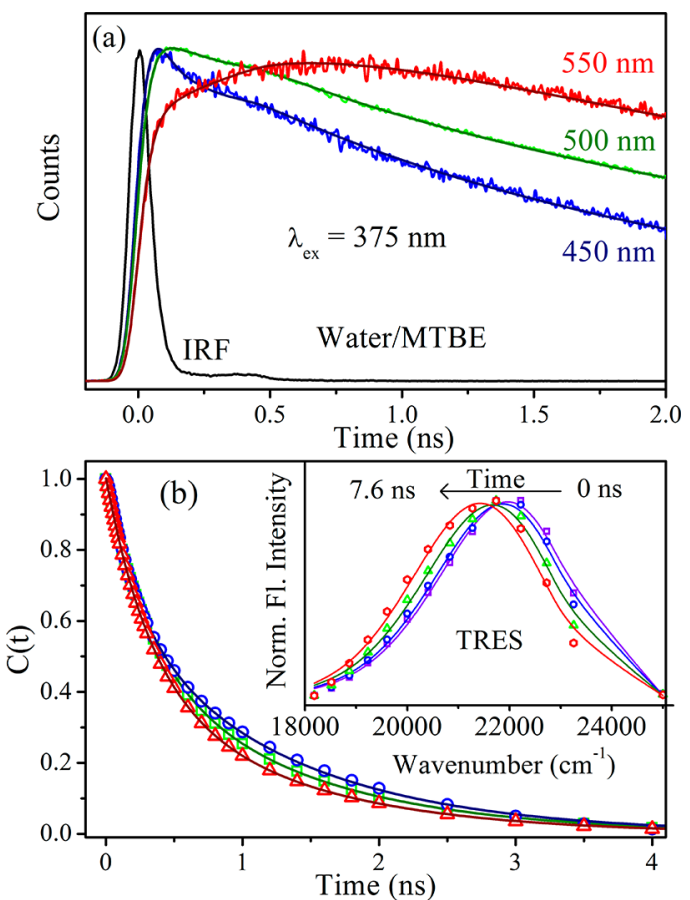

Figure 7. (a) Fluorescence decay transients $\left(\lambda_{\mathrm{ex}}=375 \mathrm{~nm}\right)$ of C500 in water/MTBE system $([$ water $]=5 \mu \mathrm{L} / \mathrm{mL})$, at $293 \mathrm{~K}$. (b) Solvation correlation function, $C(t)$, of $\mathrm{C} 500$ in water/MTBE system with different water concentration: 2.5 (blue circle), 5.0 (green square), and $10 \mu \mathrm{L} / \mathrm{mL}$ (red triangle) at $293 \mathrm{~K}$. TRES for C500 in water/MTBE system ([water] $=5 \mu \mathrm{L} / \mathrm{mL})$ at $293 \mathrm{~K}$ is shown in the inset.

transients of C500 in the water/MTBE system $(5 \mu \mathrm{L} / \mathrm{mL})$ at various wavelengths across the emission spectrum. The decay transient at $400 \mathrm{~nm}$ (blue end) is fitted triexponentially with time constants of 50,1120, and 3870 ps. For the extreme red wavelength $(550 \mathrm{~nm})$, a distinct rise component of 510 ps is produced along with the decay components of 4770 ps. The difference in transients in the red and blue ends clearly point to the presence of solvation in the system. ${ }^{7,22,34}$ The inset of Figure $7 \mathrm{~b}$ depicts the constructed TRES, and the corresponding $C(t)$ can be fitted biexponentially with time constants of $0.30 \mathrm{~ns}$ (46\%) and $1.22 \mathrm{~ns}$ (54\%) (Figure $7 \mathrm{~b}$ and Table 3). With an increase in the water concentration, the dynamics become faster (Figure $7 \mathrm{~b}$ and Table 3 ). The decrease in $\left\langle\tau_{\mathrm{s}}\right\rangle$ with increasing water content is associated with the increase of bulk type of water molecules consistent with these in reverse micelles with higher hydration numbers. $34,40,52$

Table 3. Solvent Correlation Data for C500 in Water/MTBE Mixture at Various Water Concentrations ${ }^{a}$

$\begin{array}{ccccccc}\begin{array}{c}\text { water } \\ (\mu \mathrm{L} / \mathrm{mL})\end{array} & \begin{array}{c}\text { fluorescence peak } \\ (\mathrm{nm})\end{array} & a_{1} & \begin{array}{c}\tau_{1} \\ (\mathrm{~ns})\end{array} & a_{2} & \begin{array}{c}\tau_{2} \\ (\mathrm{~ns})\end{array} & \begin{array}{c}\left\langle\tau_{\mathrm{s}}\right\rangle \\ (\mathrm{ns})\end{array} \\ 2.5 & 454 & 0.62 & 1.23 & 0.38 & 0.22 & 0.85 \\ 5.0 & 459 & 0.54 & 1.22 & 0.46 & 0.30 & 0.79 \\ 10 & 463 & 0.46 & 1.18 & 0.54 & 0.32 & 0.71\end{array}$

${ }^{a} \tau_{\mathrm{i}}$ represents the solvation correlation time constants, $a_{\mathrm{i}}$ represents its relative contribution, and $\left\langle\tau_{\mathrm{s}}\right\rangle\left(=\sum a_{\mathrm{i}} \tau_{\mathrm{i}}\right)$ is the average solvation time constant. 
Table 4. Solvent Correlation Data for C-500 in Water/MTBE Mixture ([water $]=5 \mu \mathrm{l} / \mathrm{mL}$ ) at Different Temperatures and Activation Energy Value ${ }^{a}$

\begin{tabular}{|c|c|c|c|c|c|c|c|}
\hline$T(\mathrm{~K})$ & fluorescence peak (nm) & $a_{1}$ & $\tau_{1}(\mathrm{~ns})$ & $a_{2}$ & $\tau_{2}(\mathrm{~ns})$ & $\left\langle\tau_{\mathrm{s}}\right\rangle(\mathrm{ns})$ & $E_{\text {act }}\left(\mathrm{kcal} \mathrm{mol}^{-1}\right)$ \\
\hline 278 & 459 & 0.28 & 0.27 & 0.72 & 1.28 & 0.99 & \\
\hline 283 & 459 & 0.33 & 0.29 & 0.67 & 1.26 & 0.94 & \\
\hline 288 & 459 & 0.39 & 0.30 & 0.61 & 1.26 & 0.89 & \\
\hline 293 & 459 & 0.46 & 0.30 & 0.54 & 1.22 & 0.79 & \\
\hline 298 & 459 & 0.57 & 0.33 & 0.43 & 1.48 & 0.83 & 2.2 \\
\hline 303 & 458 & 0.53 & 0.25 & 0.47 & 1.20 & 0.70 & \\
\hline 308 & 457 & 0.58 & 0.26 & 0.42 & 1.22 & 0.66 & \\
\hline 313 & 456 & 0.60 & 0.23 & 0.40 & 1.28 & 0.65 & \\
\hline 318 & 456 & 0.65 & 0.22 & 0.35 & 1.36 & 0.61 & \\
\hline
\end{tabular}

${ }^{a} \tau_{\mathrm{i}}$ represents the solvation correlation time constants, $a_{\mathrm{i}}$ represents its relative contribution, and $\left\langle\tau_{\mathrm{s}}\right\rangle\left(=\Sigma a_{\mathrm{i}} \tau_{\mathrm{i}}\right)$ is the average solvation time constant.
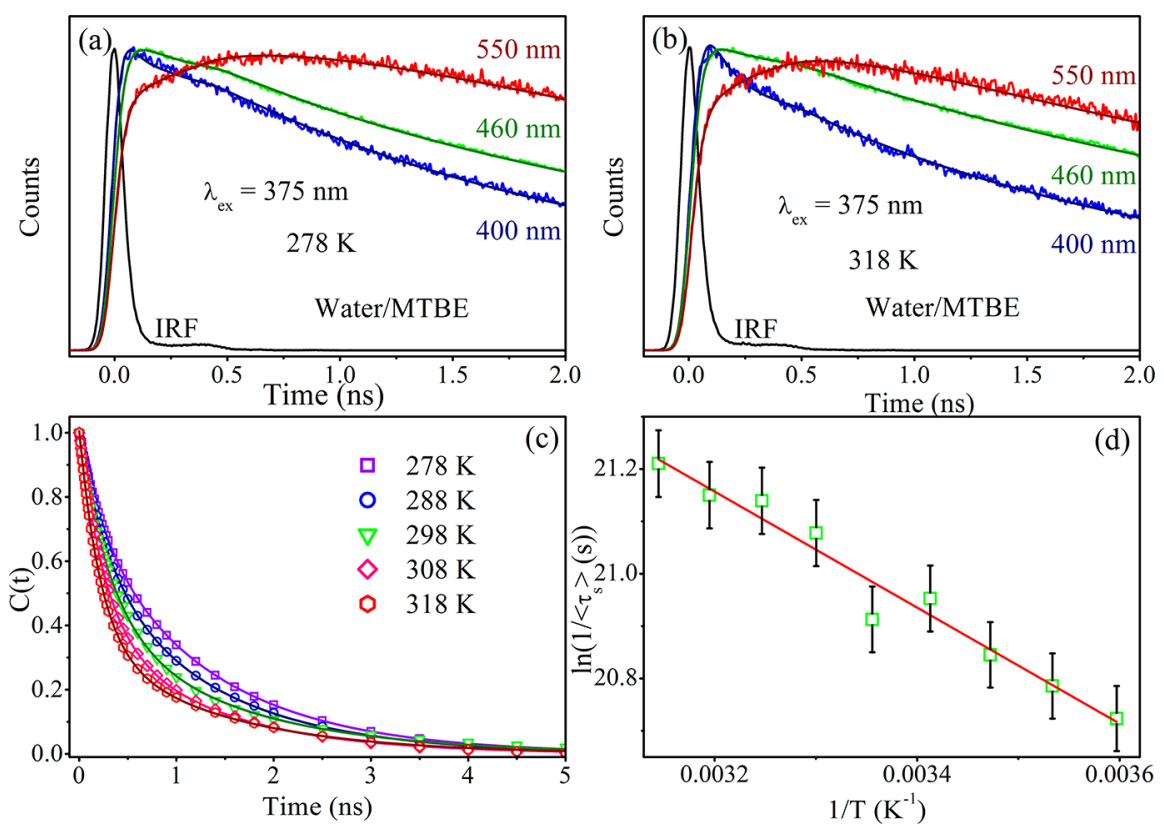

Figure 8. (a, b) Fluorescence decay transients $\left(\lambda_{\mathrm{ex}}=375 \mathrm{~nm}\right)$ of C500 in water/MTBE system $(5 \mu \mathrm{L} / \mathrm{mL}$ ), at 278 and $318 \mathrm{~K}$. (c) Solvation correlation function, $C(t)$, of C500 in water/MTBE ([water] $=5 \mu \mathrm{L} / \mathrm{mL}$ ) system, at different temperatures. (d) Plot of $\ln \left(1 / \tau_{\mathrm{s}}\right)$ against $1 / T$ for water/MTBE system ([water $]=5 \mu \mathrm{L} / \mathrm{mL})$, with linear fit.

To understand the nature of hydrogen bond formation and the possible equilibrium between the two types of water present in the cluster, we measure solvation dynamics of water, containing $5 \mu \mathrm{L} / \mathrm{mL}$ MTBE, at different temperatures (in the temperature window of $278-318 \mathrm{~K}$ ). From the temperaturedependent emission peaks of C500 (Table 4), it is evident that the fluorescence maximum of C500 exhibits a small blue shift (around $3 \mathrm{~nm}$ ). The observed blue shift indicates a less polar environment experienced by the probe at elevated temperatures due to the breakdown of hydrogen bond network followed by formation of small water clusters, similar to those reported previously. ${ }^{7,22}$ Figure $8 \mathrm{a}, \mathrm{b}$ shows the fluorescence decay transients of $\mathrm{C} 500$ at 278 and $318 \mathrm{~K}$, respectively. The figure depicts considerable difference between the decay patterns at particular wavelengths, clearly indicating temperature dependency on solvation behavior. We construct the TRES at different temperatures, and the corresponding $C(t)$ values are fitted biexponentially. A representative figure is presented (Figure $8 \mathrm{c})$, and the fitting parameters are given in Table 4. It is observed that solvation dynamics gets faster with increasing temperature and probe molecules get solvated with faster moving water molecules at the higher temperatures. This observation indicates that at the elevated temperature the hydrogen bond network present in the bulklike cluster breaks down and isolated small clusters consisting of weakly hydrogenbonded water molecules start growing, producing the faster solvation dynamics. The temperature-dependent solvation of water is associated with the dynamic exchange between free type (weakly hydrogen-bonded or partially bonded to the ether oxygen of MTBE) and bound type (strongly hydrogenbonded) water. The energetics of the exchange depends upon the strength and the number of hydrogen bonds between the water molecules at the interface and related to solvation time constant according to Arrhenius type of activation energy barrier crossing model by the following equation: ${ }^{7,22,40}$

$$
k_{\mathrm{bf}} \approx \frac{1}{\left\langle\tau_{\mathrm{s}}\right\rangle}=A \exp \left(\frac{-E_{\mathrm{act}}}{R T}\right)
$$

where $\left\langle\tau_{s}\right\rangle$ represents the average solvation time constant $\left(\left\langle\tau_{s}\right\rangle\right.$ $\left.=\sum a_{i} \tau_{i}\right), k_{\mathrm{bf}}$ is the rate constant for bound-to-free water conversion, $A$ is the pre-exponential factor, and $E_{\text {act }}$ is the corresponding activation energy for the transition process. A plot of $\ln \left(1 /\left\langle\tau_{s}\right\rangle\right)$ versus $1 / T$ produces a good linear fit (Figure $8 \mathrm{~d})$, and the corresponding activation energy value is $2.2 \mathrm{kcal}$ 
$\mathrm{mol}^{-1}$. The observed $E_{\text {act }}$ value is smaller than the bulk hydrogen bond energy ${ }^{47,53}$ of $5 \mathrm{kcal} \mathrm{mol}^{-1}$ and, therefore, must be associated with some other bonding pattern. As already mentioned, C500 resides mainly at the cluster interface, and hence, the observed $E_{\text {act }}$ corresponds to the transition occurring at the interface. Notably, the ether (like dioxane)-water hydrogen bond energy is reported to be ca. $2.3 \mathrm{kcal} \mathrm{mol}^{-1}{ }^{54} \mathrm{In}$ the present study, the estimated hydrogen bond energy of the MTBE-water complex is $\sim 3.0 \mathrm{kcal} \mathrm{mol}^{-1}$ for each hydrogen bond. Thus, the observed $E_{\text {act }}$ is essentially the manifestation of the MTBE-water hydrogen bond energy.

From the above discussion, it is evident that temperature can change the water dynamics significantly in the MTBE continuum. Therefore, it is important to know whether this change in water dynamics can alter the reaction property of the confined water molecules. In order to address this issue, we have studied the kinetics of a standard solvolysis reaction of benzoyl chloride $(\mathrm{BzCl})$ with varying temperature. The reaction is a well-studied one in the restricted medium and is reported to follow simple first order kinetics. ${ }^{55-57}$ The decay kinetics of $\mathrm{BzCl}$ hydrolysis in the mixed system $(5 \mu \mathrm{L} / \mathrm{mL})$ at different temperatures is shown in Figure 9a. The correspond-

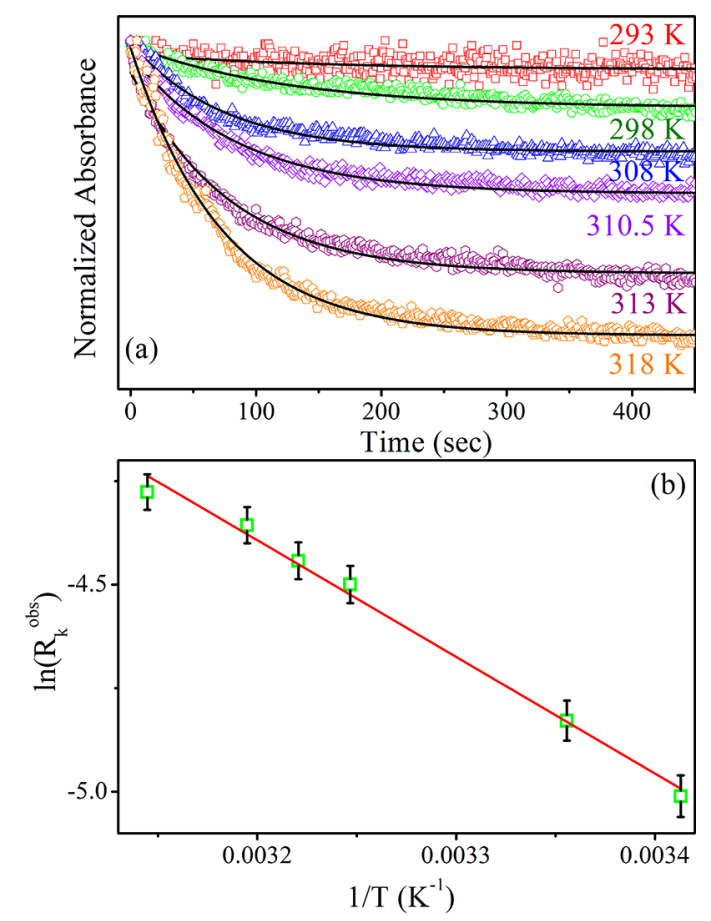

Figure 9. (a) Decay kinetics of solvolysis of benzoyl chloride monitored at $288 \mathrm{~nm}$ for water $/$ MTBE system ([water $]=5 \mu \mathrm{L} / \mathrm{mL}$ ) at different temperatures. (b) Arrhenius plot $\left(\ln \left(R_{\mathrm{k}}^{\mathrm{obs}}\right)\right.$ vs $\left.1 / T\right)$ for solvolysis of benzoyl chloride.

ing observed rate constants $\left(R_{\mathrm{k}}^{\mathrm{obs}}\right)$ of the reactions are given in Table 5. The rate constant is found to be much slower than that in pure water $\left(R_{\mathrm{k}}=1.1 \mathrm{~s}^{-1}\right){ }^{58}$ indicating the reaction occurs at the interface of the clusters. It has already been confirmed that free type interfacial water molecules act as the nucleophile in the solvolysis reaction. ${ }^{52}$ The observed acceleration of $R_{\mathrm{k}}^{\text {obs }}$ with temperature (Table 5) is thus due to the increased fraction of the interfacial free water molecules at elevated temperatures (Table 4) as has been observed in the present solvation dynamics study. In order to determine the dependency of the rate of the reaction on temperature, we apply the Arrhenius
Table 5. Rate Constants (observed, $R_{\mathrm{k}}^{\mathrm{obs}}$ ) for Solvolysis of Benzoyl Chloride in Water/MTBE Mixture ([water $]=5 \mu \mathrm{l}$ / $\mathrm{mL}$ ) at Different Temperatures and Activation Energy Value

\begin{tabular}{ccc}
$T(\mathrm{~K})$ & $R_{\mathrm{k}}^{\mathrm{obs}}\left(\mathrm{s}^{-1}\right)$ & $E_{\text {act }}\left(\mathrm{kcal} \mathrm{mol}^{-1}\right)$ \\
293.0 & 0.007 & \\
298.0 & 0.008 & \\
308.0 & 0.011 & 5.6 \\
310.5 & 0.012 & \\
313.0 & 0.013 & \\
318.0 & 0.014 & \\
\hline
\end{tabular}

model and plot $\ln \left(R_{\mathrm{k}}^{\text {obs }}\right)$ against $1 / T$ (Figure $\left.9 \mathrm{~b}\right)$. Reasonably good linear fit with the $E_{\text {act }}^{(\mathrm{rcn})}$ value of $5.6 \mathrm{kcal} \mathrm{mol}^{-1}$ is obtained. Note that the activation energy values obtained from the kinetic measurements $\left(E_{\text {act }}^{(\mathrm{rcn})}\right)$ are higher than those obtained from the solvation measurements $\left(E_{\mathrm{act}}^{(\text {solv })}\right)$. This is because solvolysis in confined systems could be assumed to take place through two steps. ${ }^{52}$ In the initial step, free water molecules are formed at the interface, which corresponds to the $E_{\text {act }}^{(\text {solv })}$ values. In the following step, these free type water molecules act as a nucleophile to bring about the solvolysis process. This difference in $E_{\text {act }}^{(\mathrm{rcn})}$ values confirms our earlier observation that at the cluster interface there exists heterogeneous hydrogen bonding between the ether oxygen of MTBE and water along with water-water hydrogen bond, and breaking-remaking of such bonds contributes to the slow solvation in concentrated water-MTBE mixture.

\section{CONCLUSIONS}

In summary, the present study investigates the effect of hydrophobic interaction on the structure, dynamics, and reactivity of water in the presence of a hydrophobic molecule MTBE. DLS measurements confirm the formation of nanometer sized molecular clusters in both the MTBE and water continuum. Vibrational shift in FTIR studies confirm the MTBE-water complexation to occur through hydrogen bonding. The dynamics of solvation of the clusters is successfully probed by the solvatochromic dye C500. Both steady-state absorption and emission spectra show the dye to reside in the solvation shell of the MTBE-water interface. Femto- and picosecond-resolved fluorescence studies successfully probes the modification of water solvation dynamics due to hydrophobic interaction, in both the MTBE and water continuum. Theoretical calculations predict the possible hydrogen bonding interaction in MTBE-water complexes. Calculated Gibbs free energy changes for different complexes are consistent with experimental results. Solvation dynamics becomes faster with increasing temperature due to the breakage of tetrahedral hydrogen bond network in the water clusters. The activation energy for the process has been calculated to be $2.2 \mathrm{kcal} \mathrm{mol}^{-1}$, which is similar to the hydrogen bond energy of a typical ether-water bond. Temperature dependent dynamics of water solvation has been well manifested in the altered reaction property of confined water molecules with temperature. Solvolysis of $\mathrm{BzCl}$ shows increased reaction kinetics with temperature and is attributed to the formation and availability of free water molecules at the interface. These results might be helpful for the understanding of the hydrophobic interaction imposed by a biomolecule on water. The detailed understanding about the physicochemical properties of the MTBEwater system would also be useful for the designing of efficient removal strategy of MTBE from drinking water. 


\section{AUTHOR INFORMATION}

\section{Corresponding Author}

*E-mail: skpal@bose.res.in. Telephone: +91-33-2335 5705/6/

7/8. Fax: +91-33-2335-3477.

\section{Notes}

The authors declare no competing financial interest.

\section{ACKNOWLEDGMENTS}

This work was supported by DST, India (SR/SO/BB-15/ 2007). S.R. thanks CSIR, India for fellowship. We would like to thank Prof. Gautam Basu and Mr. Barun Majumder, Bose Institute, Kolkata for their support and help during the NMR measurements.

\section{REFERENCES}

(1) Chandler, D. Interfaces and the driving force of hydrophobic assembly. Nature 2005, 437, 640-647.

(2) Tanford, C. The hydrophobic effect and the organization of living matter. Science 1978, 200, 1012-1018.

(3) Tanford, C. Hydrophobic free energy, micelle formation and the association of proteins with amphiphiles. J. Mol. Biol. 1972, 67, 59-74.

(4) Kauzmann, W. Some Factors in the Interpretation of Protein Denaturation. Adv. Protein Chem. 1959, 14, 1-63.

(5) Pizzitutti, F.; Marchi, M.; Sterpone, F.; Rossky, P. J. How Protein Surfaces Induce Anomalous Dynamics of Hydration Water. J. Phys. Chem. B 2007, 111, 7584-7590.

(6) Vaitheeswaran, S.; Yin, H.; C. Rasaiah, J. C.; Hummer, G. Water clusters in nonpolar cavities. Proc. Natl. Acad. Sci. U.S.A. 2004, 101, 17002-17005

(7) Rakshit, S.; Saha, R; Verma, P. K.; Pal, S. K. Role of Solvation Dynamics in Excited State Proton Transfer of 1-Naphthol in Nanoscopic Water Clusters Formed in a Hydrophobic Solvent. Photochem. Photobiol. 2012, 88, 851-859.

(8) Yang, C.; Li, W.; Wu, C. Laser Light-Scattering Study of Solution Dynamics of Water/Cycloether Mixtures. J. Phys. Chem. B 2004, 108 , 11866-11870.

(9) Takano, K.; Yamagata, Y.; Yutani, K. Buried water molecules contribute to the conformational stability of a protein. Protein Eng. 2003, 16, 5-9.

(10) Ernst, J.; Clubb, R.; Zhou, H.; Gronenborn, A.; Clore, G. Demonstration of positionally disordered water within a protein hydrophobic cavity by NMR. Science 1995, 267, 1813-1817.

(11) Rashin, A. A.; Iofin, M.; Honig, B. Internal cavities and buried waters in globular proteins. Biochemistry 1986, 25, 3619-3625.

(12) Nickolov, Z. S.; Ohno, K.; Matsuura, H. FTIR-ATR Studies of the Hydration of 15-Crown-5 and 18-Crown-6 in Aqueous Solutions. J. Phys. Chem. A 1999, 103, 7544-7551.

(13) Iwamoto, R; Matsuda, T.; Sasaki, T.; Kusanagi, H. Basic Interactions of Water with Organic Compounds. J. Phys. Chem. B 2003, 107, 7976-7980

(14) Besnard, M.; Danten, Y.; Tassaing, T. Dynamics of solitary water in benzene and hexafluorobenzene: An infrared and Raman study. J. Chem. Phys. 2000, 113, 3741-3748.

(15) Zoidis, E.; Yarwood, J.; Tassaing, T.; Danten, Y.; Besnard, M. Vibrational spectroscopic studies on the state of aggregation of water in carbon tetrachloride, in dioxane and in the mixed solvents. J. Mol. Liq. 1995, 64, 197-210.

(16) Suzuki, S.; Green, P. G.; Bumgarner, R. E.; Dasgupta, S.; Goddard, W. A.; Blake, G. A. Benzene Forms Hydrogen Bonds with Water. Science 1992, 257, 942-945.

(17) Bragg, A. E.; Kanu, G. U.; Schwartz, B. J. Nanometer-Scale Phase Separation and Preferential Solvation in THF-Water Mixtures: Ultrafast Electron Hydration and Recombination Dynamics Following CTTS Excitation of $\mathrm{I}^{-}$. J. Phys. Chem. Lett. 2011, 2, 2797-2804.

(18) Gardecki, J. A.; Maroncelli, M. Solvation and rotational dynamics in acetonitrile/propylene carbonate mixtures: a binary system for use in dynamical solvent effect studies. Chem. Phys. Lett. 1999, 301, 571-578

(19) Tominaga, K.; Walker, G. C. Femtosecond experiments on solvation dynamics of an anionic probe molecule in methanol. $J$. Photochem. Photobiol., A 1995, 87, 127-133.

(20) Luther, B. M.; Kimmel, J. R.; Levinger, N. E. Dynamics of polar solvation in acetonitrile-benzene binary mixtures: Role of dipolar and quadrupolar contributions to solvation. J. Chem. Phys. 2002, 116, 3370-3377.

(21) Molotsky, T.; Huppert, D. Solvation statics and dynamics of coumarin 153 in dioxane-water solvent mixtures. J. Phys. Chem. A 2003, 107, 8449-8457.

(22) Mitra, R. K.; Verma, P. K.; Pal, S. K. Exploration of the dynamical evolution and the associated energetics of water nanoclusters formed in a hydrophobic solvent. J. Phys. Chem. B 2009, 113, 4744-4750.

(23) Pankow, J. F.; Thomson, N. R.; Johnson, R. L.; Baehr, A. L.; Zogorski, J. S. The Urban Atmosphere as a Non-Point Source for the Transport of MTBE and Other Volatile Organic Compounds (VOCs) to Shallow Groundwater. Environ. Sci. Technol. 1997, 31, 2821-2828.

(24) Reuter, J. E.; Allen, B. C.; Richards, R. C.; Pankow, J. F.; Goldman, C. R.; Scholl, R. L.; Seyfried, J. S. Concentrations, Sources, and Fate of the Gasoline Oxygenate Methyl tert-Butyl Ether (MTBE) in a Multiple-Use Lake. Environ. Sci. Technol. 1998, 32, 3666-3672.

(25) Achten, C.; Kolb, A.; Püttmann, W.; Seel, P.; Gihr, R. Methyl tert-Butyl Ether (MTBE) in River and Wastewater in Germany. 1. Environ. Sci. Technol. 2002, 36, 3652-3661.

(26) Squillace, P. J.; Zogorski, J. S.; Wilber, W. G.; Price, C. V. Preliminary Assessment of the Occurrence and Possible Sources of MTBE in Groundwater in the United States, 1993-1994. Environ. Sci. Technol. 1996, 30, 1721-1730.

(27) Squillace, P. J.; Moran, M. J.; Lapham, W. W.; Price, C. V.; Clawges, R. M.; Zogorski, J. S. Volatile Organic Compounds in Untreated Ambient Groundwater of the United States, 1985-1995. Environ. Sci. Technol. 1999, 33, 4176-4187.

(28) Baehr, A. L.; Stackelberg, P. E.; Baker, R. J. Evaluation of the atmosphere as a source of volatile organic compounds in shallow groundwater. Water Resour. Res. 1999, 35, 127-136.

(29) Klinger, J.; Stieler, C.; Sacher, F.; Brauch, H.-J. MTBE (methyl tertiary-butyl ether) in groundwaters: Monitoring results from Germany. J. Environ. Monit. 2002, 4, 276-279.

(30) Belpoggi, F.; Soffritti, M.; Maltoni, C. Methyl-Tertiary-Butyl Ether (MTBE) - a Gasoline Additive - Causes Testicular and Lympho Haematopoietic Cancers in Rats. Toxicol. Ind. Health 1995, 11, 119-149.

(31) Nielsen, T. B.; Hvidt, S.; Keiding, S. R.; Petersen, C.; Westh, P.; Keiding, K. Thermodynamic investigations of methyl tert-butyl ether and water mixtures. Phys. Chem. Chem. Phys. 2011, 13, 1182-1188.

(32) Li, Z.; Singh, S. FTIR and Ab Initio Investigations of the MTBE-Water Complex. J. Phys. Chem. A 2008, 112, 8593-8599.

(33) Banerjee, D.; Verma, P. K.; Pal, S. K. Temperature-dependent femtosecond-resolved hydration dynamics of water in aqueous guanidinium hydrochloride solution. Photochem. Photobiol. Sci. 2009, 8, 1441-1447.

(34) Rakshit, S.; Goswami, N.; Pal, S. K. Slow Solvent Relaxation Dynamics of Nanometer Sized Reverse Micellar Systems Through Tryptophan Metabolite, Kynurenine. Photochem. Photobiol. 2012, 88, $38-45$.

(35) Horng, M. L.; Gardecki, J. A.; Papazyan, A.; Maroncelli, M. Subpicosecond measurements of polar solvation dynamics: coumarin 153 revisited. J. Phys. Chem. 1995, 99, 17311-17337.

(36) Frisch, M. J.; Trucks, G. W.; Schlegel, H. B.; Scuseria, G. E.; Robb, M. A.; Cheeseman, J. R.; Montgomery, J. A., Jr.; Vreven, T.; Kudin, K. N.; Burant, J. C.; Millam, J. M.; Iyengar, S. S.; Tomasi, J.; Barone, V.; Mennucci, B.; Cossi, M.; Scalmani, G.; ; Rega, N.; Petersson, G. A.; Nakatsuji, H.; Hada, M.; Ehara, M.; Toyota, K.; Fukuda, R.; Hasegawa, J.; Ishida, M.; Nakajima, T.; Honda, Y.; Kitao, O.; Nakai, H.; Klene, M.; Li, X.; Knox, J. E.; Hratchian, H. P.; Cross, J. B.; Adamo, C.; Jaramillo, J.; Gomperts, R.; Stratmann, R. E.; Yazyev, 
O.; Austin, A. J.; Cammi, R.; Pomelli, C.; Ochterski, J. W.; Ayala, P. Y.; Morokuma, K.; Voth, G. A.; Salvador, P.; Dannenberg, J. J.; Zakrzewski, V. G.; Dapprich, S.; Daniels, A. D.; Strain, M. C.; Farkas, O.; Malick, D. K.; Rabuck, A. D.; Raghavachari, K.; Foresman, J. B.; Ortiz, J. V.; Cui, Q.; Baboul, A. G.; Clifford, S.; Cioslowski, J.; Stefanov, B. B.; Liu, G.; Liashenko, A.; Piskorz, P.; Komaromi, I.; Martin, R. L.; Fox, D. J.; Keith, T.; Al-Laham, M. A.; Peng, C. Y.; Nanayakkara, A.; Challacombe, M.; Gill, P. M. W.; Johnson, B.; Chen, W.; Wong, M. W.; Gonzalez, C.; Pople, J. A. Gaussian 03, revision C.02; Gaussian, Inc.: Wallingford, CT, 2004.

(37) Dunn, M. E.; Pokon, E. K.; Shields, G. C. Thermodynamics of Forming Water Clusters at Various Temperatures and Pressures by Gaussian-2, Gaussian-3, Complete Basis Set-QB3, and Complete Basis Set-APNO Model Chemistries; Implications for Atmospheric Chemistry. J. Am. Chem. Soc. 2004, 126, 2647-2653.

(38) Takamuku, T.; Yamaguchi, A.; Tabata, M.; Nishi, N.; Yoshida, K.; Wakita, H.; Yamaguchi, T. Structure and dynamics of 1,4-dioxanewater binary solutions studied by X-ray diffraction, mass spectrometry, and NMR relaxation. J. Mol. Liq. 1999, 83, 163-177.

(39) Rakshit, S.; Saha, R.; Singha, A.; Seddigi, Z. S. A.; Pal, S. K. Molecular Interaction, Co-solubilisation of Organic Pollutants and Ecotoxicity of a Potential Carcinogenic Fuel Additive MTBE in Water. J. Mol. Liquids 2013, In press.

(40) Verma, P. K.; Saha, R.; Mitra, R. K.; Pal, S. K. Slow water dynamics at the surface of macromolecular assemblies of different morphologies. Soft Matter 2010, 6, 5971-5979.

(41) Saha, R.; Rakshit, S.; Mitra, R. K.; Pal, S. K. Microstructure, Morphology, and Ultrafast Dynamics of a Novel Edible Microemulsion. Langmuir 2012, 28, 8309-8317.

(42) Jimenez, R.; Fleming, G. R.; Kumar, P. V.; Maroncelli, M. Femtosecond solvation dynamics of water. Nature 1994, 369, 471473.

(43) Jarzeba, W.; Walker, G. C.; Johnson, A. E.; Kahlow, M. A.; Barbara, P. F. Femtosecond microscopic solvation dynamics of aqueous solutions. J. Phys. Chem. 1988, 92, 7039-7041.

(44) Nandi, N.; Bagchi, B. Dielectric Relaxation of Biological Water. J. Phys. Chem. B 1997, 101, 10954-10961.

(45) Suresh, S. J.; Naik, V. M. Hydrogen bond thermodynamic properties of water from dielectric constant data. J. Chem. Phys. 2000, 113, 9727-9732.

(46) Silverstein, K. A. T.; Haymet, A. D. J.; Dill, K. A. The Strength of Hydrogen Bonds in Liquid Water and Around Nonpolar Solutes. J. Am. Chem. Soc. 2000, 122, 8037-8041.

(47) Feyereisen, M. W.; Feller, D.; Dixon, D. A. Hydrogen bond energy of the water dimer. J. Phys. Chem. 1996, 100, 2993-2997.

(48) Sharp, K. A.; Madan, B.; Manas, E.; Vanderkooi, J. M. Water structure changes induced by hydrophobic and polar solutes revealed by simulations and infrared spectroscopy. J. Chem. Phys. 2001, 114, $1791-1796$.

(49) Gottlieb, H. E.; Kotlyar, V.; Nudelman, A. NMR Chemical Shifts of Common Laboratory Solvents as Trace Impurities. J. Org. Chem. 1997, 62, 7512-7515.

(50) Abraham, R. J.; Mobli, M. An NMR, IR and theoretical investigation of $1 \mathrm{H}$ Chemical Shifts and hydrogen bonding in phenols. Magn. Reson. Chem. 2007, 45, 865-877.

(51) Sahu, K.; Mondal, S. K.; Roy, D.; Karmakar, R.; Bhattacharyya, K. Slow solvation dynamics of 4-AP and DCM in binary mixtures. $J$. Photochem. Photobiol., A 2005, 172, 180-184.

(52) Verma, P. K.; Makhal, A.; Mitra, R. K.; Pal, S. K. Role of solvation dynamics in the kinetics of solvolysis reactions in microreactors. Phys. Chem. Chem. Phys. 2009, 11, 8467-8476.

(53) Moore Plummer, P. L. Applicability of semi-empirical methods to the study of small water clusters: cubic structures for $\left(\mathrm{H}_{2} \mathrm{O}\right) \mathrm{n}(\mathrm{n}=$ 8, 12, 16). J. Mol. Struct.: THEOCHEM 1997, 417, 35-47.

(54) Buz'ko, V. Y.; Sukhno, I. V.; Panyushkin, V. T.; Ramazanova, D. $\mathrm{N}$. Theoretical investigation of 1,4-dioxane complexes with water in the chair conformation by semiempiric MNDO/PM3 method. $J$. Struct. Chem. 2005, 46, 596-602.
(55) Garcia-Rio, L.; Leis, J. R.; Moreira, J. A. Reactivity in water/oil microemulsions. Influence of sodium bis(2-ethylhexyl) sulfosuccinate/ isooctane/water microemulsions on the solvolysis mechanism of substituted benzoyl chlorides. J. Am. Chem. Soc. 2000, 122, 1032510334.

(56) Garcia-Rio, L.; Leis, J. R.; Iglesias, E. Influence of water structure on solvolysis in water-in-oil microemulsions. J. Phys. Chem. 1995, 99, 12318-12326.

(57) Fernández, E.; García-Río, L.; Godoy, A.; Leis, J. R. Reactivity in w/o microemulsions. Activation parameters for solvolysis in AOT/ isooctane/water systems. New J. Chem. 2003, 27, 1207-1215.

(58) Cabaleiro-Lago, C.; Garcia-Rio, L.; Herves, P.; Perez-Juste, J. Reactivity of benzoyl chlorides in nonionic microemulsions: potential application as indicators of system properties. J. Phys. Chem. B 2005, 109, 22614-22622. 